\title{
Reduction of microbial biofilm formation using hydrophobic nano-silica coating on cooling tower fill material
}

\author{
Irfan Türetgen ${ }^{1 *}$ \\ IIstanbul University, Faculty of Science, Department of Biology, Istanbul Turkey
}

\begin{abstract}
A cooling tower is a heat removal device, which extracts waste heat to the atmosphere through the cooling of a water stream to a lower temperature. Cooling towers are frequently associated with biofilm problems and Legionnaires disease outbreaks. Where biofilms can cause clogging and corrosion, reduction of biofilms is important for operational reasons and public health. Therefore, effective anti-biofilm strategies are needed in practice. The aim of the present study was to reduce biofilm formation using a nano-hydrophobic coating on cooling tower fill materials - polypropylene cooling tower fill material was coated with nano-silica. The effectiveness of the hydrophobic coating was investigated for a 6 -month test period in a model cooling tower system, by monthly counting of the surface-associated bacteria using an epifluorescence microscope. A significant reduction (up to $4 \log$ ) in surface-associated bacteria was observed on coated test samples in comparison to uncoated control coupons. This study is the first report regarding the use of nano-silica coatings on cooling tower fills. The coating can be easily fabricated and the range of possible applications can be expanded to include a variety of conditions.
\end{abstract}

Keywords: biofilm, nano-silica, hydrophobic coating, cooling tower, fill material

\section{INTRODUCTION}

Biofilm is a dynamic structure adhering to solid surfaces that are generally in contact with water, and consists of colonies of bacteria and usually other microorganisms that secrete a polysaccharide-based protective coating in which they are encased (Costerton, 1999). Bacterial species have a strong tendency to colonize surfaces. Bacteria attached to a surface are more resistant to antimicrobial agents than free-living planktonic cells and biofilms are a serious problem in many areas, including the food, environmental, and industrial sectors (Zhong et al., 2013). The ability of aquatic bacteria to adhere to surfaces and to form biofilm has major implications in a variety of man-made water systems, where biofilm can create a persistent source of contamination (Türetgen, 2004; Türetgen et al., 2012).

Cooling towers are heat rejection appliances and are integral to industrial processes in power plants, air-conditioning systems, telecommunication devices, etc. To achieve better cooling performance, a medium called 'fill' is used to increase the surface area of contact between the air and water flow. Fill is composed of thin sheets of plastic polymer material to create an increased surface area upon which the water flows. It is a natural tendency of microorganisms to attach to wet surfaces, multiply and embed themselves in a slimy matrix composed of extracellular polymeric substances that they produce, forming a biofilm. Biofilm formation in cooling tower water systems is undesirable for operational and public health reasons. These systems provide an ideal environment for bacteria to grow and multiply (Torvinen et al., 2014; Türetgen et al., 2005). The best known pathogen in cooling towers is the Legionella bacteria, which causes Legionnaires' disease. Bacterial biofilms in cooling towers develop most frequently on heat transfer surfaces as temperatures there favour the rapid growth of L. pneumophila (Harris, 2000).

Nanotechnology is defined as the design, characterization,

\footnotetext{
* To whom all correspondence should be addressed.

- +90 21245557 00; Fax: + 9021252805 27;

e-mail: turetgen@istanbul.edu.tr

Received 29 April 2014; accepted in revised form 3 March 2015
}

production and application of structures, devices and systems by controlling shape and size at the nano-scale $(<100 \mathrm{~nm})$. Over the past 3 decades, nanotechnology has emerged as a promising strategy to resolve the technological impasses incurred in various branches of science and engineering, with numerous new and exciting applications in medicines, cosmetics, clothing, electronics and environmental protection (Ovissipour et al., 2014) having been made. The surface properties of the materials can be changed by coating application or surface modification, to create the desired anti-adhesion characteristics without altering the bulk properties of materials. Various coatings have been developed in order to achieve a variety of functional characteristics, including anti-scratch, anti-reflective, anti-fogging, anti-microbial or self-cleaning properties (Türetgen et al., 2012; Ovissipour et al., 2014; Zhang et al., 2014). Attempts have been made to reduce biofilm formation by coating surfaces with antimicrobials, by the incorporation of antimicrobial products into surface materials or by modifying the surface's physicochemical properties (Hetrick et al., 2009; Bruellhoff et al., 2010; Simoes et al., 2010, Chen et al., 2013). Silica or silicon dioxide is the material that is used to make glass. Nano-sized silica or nano-silica is frequently employed for a variety of applications, mainly because of its easy functionalization, low toxicity and stability (Mauline et al., 2013; Slomberg et al., 2013). The functionalized silica nanoparticles attached to the surface give an effect similar to the water repellency of lotus leaves (Hetrick et al., 2009).

Based on these characteristics, a nano-silica coating was tested in cooling tower water conditions on polypropylene fill material. The objective of the present study was to reduce the slimy biofilm formation in cooling towers using hydrophobic nano-silica coating on fill material, to ensure better cooling of water, longer material life and less clogging of the fills.

\section{METHODS}

\section{Model system and experimental set-up}

The study was conducted in a $100-\ell$ polypropylene labscale cooling tower model system, under constant hydraulic 
conditions. It was equipped with a recirculating pump in the basin and a heat source to facilitate evaporation, as described previously (Türetgen et al., 2012). The covering lid had openings to ensure fresh air and daylight entry, similar to a real cooling tower. A supply of potable water was used to replenish water lost by evaporation and blowdown (partial draining). The use of a model system was preferred because of the control this achieved over operating parameters and monitoring. Throughout the experiment, the water temperature was kept constant at $37^{\circ} \mathrm{C}$. Test coupons were fixed and did not make any contact with each other. Biofilms were allowed to develop for 6 months on coupons within the model system. No chemicals (disinfectant, $\mathrm{pH}$ regulators or anti-scaling agents) were added to the system, to exclude their negative effects on microorganisms and biofilm formation.

\section{Test coupons and coating}

Original polypropylene fill material sheet was cut into small coupons $(5 \times 2 \mathrm{~cm})$ for easy examination, cleaned using $70 \%$ ethanol, rinsed with distilled water, left to air dry, and coated with hydrophobic nano-silica. Liquid nano-silica is a colourless, transparent and ready-to-use product, which was sprayed directly for full coverage on the samples at ambient temperature and cured by being left to air dry for $48 \mathrm{~h}$. Nano-silica was granted from Artekya LTD (Istanbul, Turkey). The silica $\left(\mathrm{SiO}_{2}\right)$ nanoparticle size was $\sim 50 \mathrm{~nm}$, which was modified by active fluor atoms. The liquid form of the coating contains a maximum of $60 \%$ hydrocarbon solvent. The stability of the coating was characterized using a portable pull-off adhesion tester (Elcometer 510, US) after $24 \mathrm{~h}$ of curing. The average overall adhesion value of the coating was recorded as 1.5 , which corresponds to (good, in terms of the overall adhesion rating presented by McDonald et al. (1995). The coating was stable on surfaces - no weight loss, discoloration or peeling was observed on all of the coated test coupons after 6 months.

\section{Contact angle and surface roughness measurements}

The contact angle measurement of the test coupons was carried out using a contact angle goniometer with deionized water at ambient temperature, before the coupons were immersed in water for the experiment. The measurement of coated samples was done right after the 24-h curing time. Each coated and uncoated sample was measured 6 times. Surface roughness was assessed by a white light optical profiler (Wyko NT1100, US) in the vertical scanning mode, which is a non-contact optical profiling system that provides high vertical resolution. Scan speed was set to $7.2 \mu \mathrm{m} / \mathrm{s}$. Representative roughness parameter is the mean average roughness $\left(R_{\mathrm{a}}\right)$ of 3 measurements. $R_{\mathrm{a}}$ is the arithmetic average of the absolute values of the roughness profile ordinates.

\section{DAPI staining}

4',6-diamidino-2-phenylindole (DAPI) (Sigma-Aldrich, US) is a fluorescent stain that binds strongly to A-T rich regions in DNA. Four coupons were removed monthly for analysis and staining, carried out in triplicate. Coupons were rinsed with phosphate-buffered saline to remove any unattached cells and then stained with $1.0 \mu \mathrm{g} / \mathrm{m} \ell$ DAPI solution for epifluorescence microscopy. After 30-min incubation with the dye, in the dark and at $37^{\circ} \mathrm{C}$, samples were washed with filter-sterilized double-distilled water (Rodriguez et al. 1992). The air-dried coupons were coverslipped and examined using an epifluorescent microscope equipped with a $100 \mathrm{~W}$ mercury lamp (Nikon $80 \mathrm{i}$, Japan). The total number of bacteria was calculated from 20 randomly-chosen microscopic fields.

\section{Statistical analysis}

Blue-coloured DAPI signal counts were $\log _{10}$ transformed and standard errors of the means were calculated. To keep the individual numbers manageable, a 'log reduction' term was used. One log reduction means a 10 -fold decrease in bacterial numbers. Differences between variables were tested for significance using a t-test; differences were considered significantly different when $P<0.05$. Statistical analyses were performed using SPSS Version 11.0 program.

\section{RESULTS}

The efficacy of the hydrophobic coating on fill material over a 6-month period was evaluated to determine the effectiveness in controlling biofilm formation in a model recirculating water system simulating cooling tower water system conditions. The biofilm reproducibility and physicochemical properties (temperature, evaporation, $\mathrm{pH}$, total dissolved solids) of the bulk water were compared to a full-scale cooling tower system examined in a previous study, to reveal how representative the model system is (Türetgen, 2004). The results of the present study clearly showed that total bacterial counts on nano-silica coated test surfaces, determined by epifluorescence microscopy, were significantly lower $(P<0.05)$ than that of uncoated polypropylene samples. After the first month the reduction was more than $2 \log$, which gradually increased till the end of the 6-month period. After the sixth month, a 4 log difference (Table 1) was observed between test and control coupons. The differences between coated and uncoated polypropylene coupons were found to be statistically significant $(P<0.05)$ (Fig. 1).

The total bacterial counts on nano-silica coated samples were recorded as $4 \mathrm{cell} / \mathrm{cm}^{2}$ after the first month, whereas this was $355 \mathrm{cell} / \mathrm{cm}^{2}$ on uncoated polypropylene material. This result clearly indicates that hydrophobic nano-silica coating reduces biofilm formation on fill materials from the beginning of the experiment. The density of biofilm bacteria on uncoated

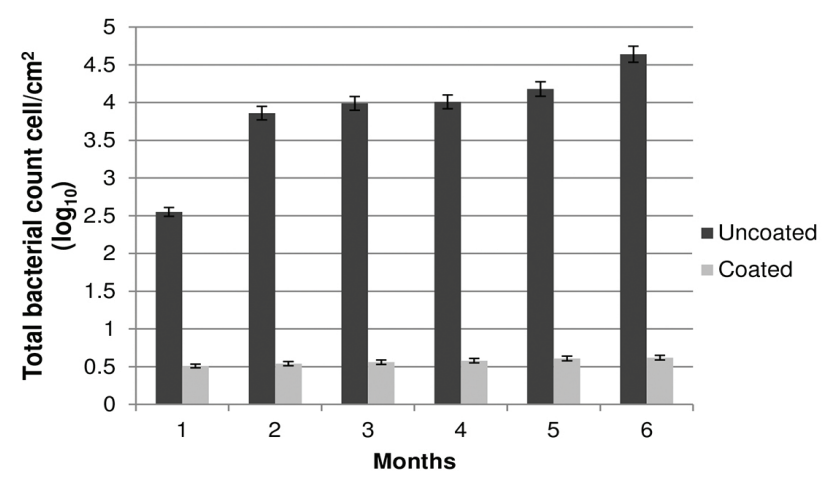

Figure 1

Total bacterial counts over time. Error bars indicate standard deviation. Results reported represent the arithmetic means of 3 replicate measurements for each of 4 coupons monthly. 
control coupons gradually increased and reached 42365 cell/ $\mathrm{cm}^{2}$ after 6 months. No significant increase $(P<0.05)$ of biofilm density on coated samples was observed during the 6-month period in terms of surface-associated total bacteria counts. The results demonstrate that a nano-silica coating could help to control bacterial biofilm formation in cooling tower water systems.

The water contact angles of the polypropylene coupons increased after coating with nano-silica, indicating that the hydrophobicity of the coated surfaces was significantly increased $(P<0.05)$ (Table 2). If the water contact angle degree is larger than $90^{\circ}$, the surface is considered to be hydrophobic (Arkles, 2006). The average water contact angle of uncoated control coupons was measured as $76.47^{\circ}$, whereas the average for coated coupons was $120.61^{\circ}$. On the other hand, the nanosilica coating improved the surface roughness by smoothing out the extruded polymer surface. The data for the test and control coupons is listed in Table 3. Surface roughness was measured as average roughness $\left(R_{\mathrm{a}}\right)$ using an optical non-contact profiler. The coating application decreased surface roughness significantly compared to that of the uncoated control coupons $(P<0.05)$. The average roughness of uncoated control coupons was measured as $1.32 \mu \mathrm{m}$, whereas coated coupons' average roughness was $0.31 \mu \mathrm{m}$.

\section{DISCUSSION}

The emergence of biofilm-related problems clearly shows that new biofilm control strategies are required. Ideally, preventing biofilm formation would be a better option than treating or cleaning it. However, there is presently no known technique that is able to totally prevent the formation of unwanted biofilms. Various strategies to reduce the accumulation of microbial biofilms have been studied over the years, with various degrees of success (Hetrick et al., 2009; Türetgen et al., 2012; Mauline et al., 2013). In different industrial settings, a range of biocides and toxic metals have been used for sanitizing purposes and/or biofilm reduction. It is known that the preconditioning of surfaces with hydrophobic coatings significantly discourages bacterial attachment and adhesion to these surfaces. Antibacterial coatings have also been used in the past with low success, due to the emergence of resistant strains (Simoes et al., 2010; Epstein et al., 2010). Aside from this, biofilm bacteria are highly resistant to antimicrobial agents. Using coatings with antimicrobial agents could lead to selection for resistance and could even induce biofilm formation (Hoffman et al., 2005). Previous approaches have mostly used antimicrobial substances to counter biofilms. The use of a nano-silica coating did not include any antimicrobial agents, which could count as an

\begin{tabular}{|c|c|c|c|}
\hline \multicolumn{4}{|c|}{$\begin{array}{l}\text { Table } 1 \\
\log _{10} \text { based total bacterial cell counts on surfaces and log reductions }\end{array}$} \\
\hline \multirow[b]{2}{*}{ Months } & \multicolumn{2}{|c|}{ Total bacterial count cell $/ \mathrm{cm}^{2}\left(\log _{10}\right)$} & \multirow[b]{2}{*}{ Log reduction } \\
\hline & Uncoated surface & Coated surface & \\
\hline 1 & 2.55 & 0.60 & 2.0 \\
\hline 2 & 3.86 & 0.54 & 3.0 \\
\hline 3 & 3.99 & 0.56 & 3.5 \\
\hline 4 & 4.01 & 0.58 & 3.5 \\
\hline 5 & 4.18 & 0.61 & 3.5 \\
\hline 6 & 4.64 & 0.62 & 4.0 \\
\hline
\end{tabular}

Table 2

Water contact angles (by degree) of polypropylene coupons were measured before (control coupons) and after curing of the coating application (coated test coupons), at the beginning of the experiment.

\begin{tabular}{|l|c|c|}
\hline \multirow{2}{*}{ No. of measurements } & \multicolumn{2}{|c|}{ Contact angles $\left({ }^{\circ}\right)$} \\
\cline { 2 - 3 } & Control coupons & Coated test coupons \\
\hline 1 & 77.06 & 102.81 \\
\hline 2 & 75.98 & 103.08 \\
\hline 3 & 76.16 & 102.77 \\
\hline 4 & 77.22 & 101.96 \\
\hline 5 & 75.55 & 102.53 \\
\hline 6 & 76.85 & 102.56 \\
\hline
\end{tabular}

Table 3

Average roughness, $\mathrm{Ra}(\mu \mathrm{m})$ results for 6 different polypropylene coupons, uncoated (control) and coated with nano-silica

\begin{tabular}{|l|c|c|c|c|c|c|}
\hline & Uncoated (1) & Uncoated (2) & Uncoated (3) & Coated (4) & Coated (5) & Coated (6) \\
\hline $\mathrm{Ra}(\mu \mathrm{m})$ & 1.37 & 1.28 & 1.31 & 0.38 & 0.30 & 0.25 \\
\hline & & & & & & \\
\hline
\end{tabular}


advantage. One of the shortcomings of bactericidal surfaces is that they could end up being covered with macromolecules and dead microorganisms, and then lose their antimicrobial function (Klibanov, 2007).

As underlined by Zhong et al. (2013) and Oliveira et al. (2001), bacteria are generally more likely to adhere to hydrophobic surfaces rather than hydrophilic surfaces. But Shaer et al. (2012) have presented findings that demonstrate that hydrophobic coatings can inhibit biofilms. Simoes et al. (2010) concluded that adhesion mechanisms other than physicochemical surface properties may play a determining role in bacterial adherence ability. Some interactions (e.g. electrostatic, steric) or conditions (temperature, $\mathrm{pH}$, ionic strength of bulk water) can combine to adversely influence the adhesion of heterotrophic bacteria on silica-coated hydrophobic surfaces. Biofilm inhibition could be also attributed to the coating's chemical inertness, low surface free energy or coating smoothness (Chen et al., 2013). The author is of the opinion that high shear forces with induced water flow in recirculating cooling tower water conditions may make attachment more difficult in the presence of a nano-silica coating. The number of bacteria that may adhere and their ability to grow and spread on surfaces is greatly influenced by not only the bacteria themselves but also the physicochemical properties of the bulk water (Oliveira et al., 2001). The physicochemical properties of water in cooling tower systems differ; cooling systemes generally have higher temperatures $\left(40-50^{\circ} \mathrm{C}\right.$ ), higher $\mathrm{pH}$ values (up to 11 ) and more elevated total dissolved solids values compared to drinking water networks (Türetgen, 2004). On the other hand; the surface roughness of solid materials has been recognized as one of many important factors for surface-bacteria interactions. Studies have shown that the surface roughness of materials strongly influences the degree of bacterial adhesion to surfaces (Mitik-Dineva et al., 2009; Truong et al., 2010). Cech et al. (2013) also observed a reduction of surface roughness for different materials after the coating process.

Low-cost nano-silica, with high strength and toughness, high temperature resistance and corrosion resistance, offers an alternative and novel perspective for use in particular areas (Ovissipour et al., 2014). The easy coating process enables preparation of a hydrophobic surface without any need for expensive compounds or techniques. The coating can be easily produced using dip coating or spraying. Cooling towers are often used in hotels, shopping malls and industrial plants. It is widely known that cooling tower maintenance is heavily neglected (Türetgen et al., 2005), resulting in expensive maintenance charges, shortened material life, inefficient cooling, excessive energy consumption and public health risk due to Legionella bacteria dissemination. While novel anti-biofilm approaches are still in the nascent phases of development, attention needs to be given to appropriate management of cooling towers, given their frequent association with the deadly Legionnaires' disease.

\section{CONCLUSION}

As an alternative strategy to fight against biofilms, nano-silica coating has been proposed for the reduction of biofilm formation in manufactured water systems. In this work, the author describes a simple coating procedure for cooling tower fills, as appropriate biofilm control is essential to maintain maximum heat transfer efficiency in cooling towers. This study is the first report regarding the use of nano-silica coatings on cooling tower fill material. The outcomes of this study should attract the attention of cooling tower manufacturers and cooling tower operators needing to maintain water quality standards. The range of possible applications of this coating can be expanded to other conditions or contexts. Due to increasing constraints on environmental discharge of disinfectants and the increasing restrictions on the use of biocides, as well as a desire to reduce the costs of system maintenance, alternative methods to reduce biofilms in industrial water systems hold much promise. The impacts of similar coatings on biofilm formation have further implications, and require further study.

\section{ACKNOWLEDGEMENTS}

This work was supported by TÜBITAK - The Scientific and Technical Research Council of Turkey, Project Number 1005 - 114Z191.

\section{REFERENCES}

ARKLES B (2006) Hydrophobicity, hydrophilicity and silanes. Paint Coatings Ind. Mag. 22 (10) 114-124.

BRUELLHOFF K, FIEDLER J, MÖLLER M, GROLL J and BRENNER RE (2010) Surface coating strategies to prevent biofilm formation on implant surfaces. Int. J. Artif. Organs 33 (9) 646-653.

CECH J, PRANOV H, KOFOD G, MATSCHUK M, MURTHY S and TABORYSKI R (2013) Surface roughness reduction using spraycoated hydrogen silsesquioxane reflow. Appl. Surf. Sci. 280 (1) 424-430.

CHEN M, YU Q and SUN H (2013) Novel strategies for the prevention and treatment of biofilm related infections. Int. J. Mol. Sci. 14 18488-18501.

COSTERTON JW (1999) Introduction to biofilm. Int. J. Antimicrob. Agents 11 217-221.

EPSTEIN A K, POKROYA B, SEMINARA A and AIZENBERG J (2010) Bacterial biofilm shows persistent resistance to liquid wetting and gas penetration. Proc. Natl. Acad. Sci. 108 (3) 995-1000.

HARRIS A (2000) Problems associated with biofilms in cooling tower systems. In: Keevil CV, Godfree A, Holt D and Dow C (ed.) Biofilms in the Aquatic Environment. Springer-Verlag, New York.

Anti-Biofilm Efficacy of Nitric Oxide-Releasing Silica Nanoparticles

HETRICK EM, SHIN JH, PAUL HS and SCHOENFISCH MH (2009) Anti-biofilm efficacy of nitric oxide-releasing silica nanoparticles. Biomaterials 30 2782-2789.

HOFFMAN LR, D'ARGENIO DA, MACCOSS MJ, ZHANG Z, JONES RA and MILLER SI (2005) Aminoglycoside antibiotics induce bacterial biofilm formation. Nature 436 1171-1175.

KLIBANOV AM (2007) Permanently microbicidal materials coatings. J. Mater. Chem. 17 2479-2482.

MAULINE L, GRESSIER M, ROQUES C, HAMMER P, RIBEIRO SJ, CAIUT JM and MENU MJ (2013) Bifunctional silica nanoparticles for the exploration of biofilms of Pseudomonas aeruginosa. Biofouling 29 (7) 775-788.

McDONALD DB, SHERMAN MR and PFEIFER DW (1995) The performance of bendable and nonbendable coatings for reinforcing bars in solution and cathodic debonding tests. Federal Highway Administration. Publication No. FHWA-RD-94-103. US Department of Transportation, Washington, DC.

MITIK-DINEVA N, WANG J, TRUONG VK, STODDART P, MALHERBE F, CRAWFORD RJ and IVANOVA EP (2009) Escherichia coli, Pseudomonas aeruginosa and Staphylococcus aureus attachment patterns on glass surfaces with nanoscale roughness. Curr. Microbiol. 58 268-273.

OLIVEIRA R, AZEREDO J, TEIXEIRA P and FONSECA AP (2001) The role of hydrophobicity in bacterial adhesion. In: Gilbert P, Allison D, Brading M, Verran J and Walker J (eds) Biofilm Community Interactions: Chance or Necessity? Bioline, Cardiff, UK.

OVISSIPOUR M, ROOPESH SM, RASCO BA and SABLANI SS (2014) Engineered nanoparticles (ENPs): Applications, risk assessment, and risk management in the agriculture and food sectors. In: Wang S 
(ed.) Food Chemical Hazard Detection: Development and Application of New Technologies. John Wiley \& Sons, Chichester, UK.

RODRIGUEZ GG, PHIPPS D, ISHIGURO K and RIDGWAY HF (1992) Use of a fluorescent redox probe for direct visualization of actively respiring bacteria. Appl. Environ. Microbiol. 58 1801-1808. SCHAER TP, STEWART S, HSU BB and KLIBANOV AM (2012) Hydrophobic polycationic coatings that inhibit biofilms and support bone healing during infection. Biomaterials 33 (5) 1245-1254.

SIMÕES M, PEREIRA MO and VIEIRA MJ (2010) A review of current and emergent biofilm control strategies. Food Sci. Technol. 43 (4) 573-583.

SLOMBERG DL, LU Y, BROADNAX AD, HUNTER RA, CARPENTER AW and SCHOENFISCH MH (2013) Role of size and shape on biofilm eradication for nitric oxide-releasing silica nanoparticles. Appl. Mater. Interfaces 5 (19) 9322-9329.

TORVINEN E, SUOMALAINEN S, PAULIN L and KUSNETSOV J (2014) Mycobacteria in Finnish cooling tower waters. Acta Path. Microbiol. Immun. Scand. 122 353-358.

TRUONG VK, LAPOVOK R, ESTRIN YS, RUNDELL S, WANG JY, FLUKE CJ, CRAWFORD RJ and IVANOVA EP (2010) The influence of nano-scale surface roughness on bacterial adhesion to ultrafine-grained titanium. Biomaterials 31 3674-3683.
TÜRETGEN I (2004) Comparison of the efficacy of free residual chlorine and monochloramine against biofilms in model and full scale cooling towers. Biofouling 20 81-85.

TÜRETGEN I, SUNGUR EI and COTUK A (2005) Enumeration of Legionella pneumophila in cooling tower water systems. Environ. Monit. Assess. 100 53-58.

TÜRETGEN I, SANLI YÜRÜDÜ N and NORDEN I (2012) Biofilm formation comparison of the Sanipacking cooling tower fill material against standard polypropylene fill material in recirculating model water system. Turk. J. Biol. 36 313-318.

ZHANG X, LAN P, LU Y, LI J, XU H, ZHANG J, LEE Y, RHEE JY, CHOY K L and SONG W (2014) Multifunctional antireflection coatings based on novel hollow silica nanocomposites. Appl. Mater. Interfaces 6 (3) 1415-1423.

ZHONG LJ, PANG LQ, CHE LM, WU XE and CHEN XD (2013) Nafion coated stainless steel for anti-biofilm application. Colloids Surf. B 111 252-256. 